J. Lake Sci. (湖泊科学), 2011, 23(1): 35-39

http: //www. jlakes. org. E-mail : jlakes@niglas.ac.cn

(c) 2011 by Journal of Lake Sciences

\title{
江西省万安水库对氮、磷营养盐的滞留效应”
}

\author{
胡春华 ${ }^{1,2}$, 周文斌 ${ }^{1,2}$, 钟夏莲 ${ }^{1,2}$, 王毛兰 ${ }^{1,2}$ \\ ( 1 : 南昌大学鄱阳湖环境与资源利用教育部重点实验室,南昌 330029) \\ (2: 南昌大学环境与化学工程学院, 南昌 330031)
}

摘 要: 以江西省万安水库为研究对象, 于 2007-2009 年丰、枯水期对水库进行了人库、出库水样采集, 研究了万安水库 对氮、磷营养盐的滞留效应. 结果表明, 万安水库对氮、磷营养盐存在显著滞留作用. DIN 浓度和输送通量整体均表现为 人库 $>$ 出库, 受径流量季节变化的影响, 不同时期 DIN 的滞留情况整体表现为枯水期 <丰水期; TP 浓度和输送通量整体 均表现为人库 > 出库, 不同时期的浓度滞留情况整体表现为枯水期 > 丰水期. $2007-2009$ 年间分别有 $1.57 \times 10^{4} \mathrm{t} 、 2.38 \times$ $10^{4} \mathrm{t} 、 2.95 \times 10^{4} \mathrm{t}$ 溶解态氮滞留于万安水库,2007 年和 2009 年分别有 $7.44 \times 10^{2} \mathrm{t} 、 3.65 \times 10^{3} \mathrm{t}$ 的总磷滞留于库内, 2008 年 万安水库对总磷出现负滞留, 其原因与外源输人作用、水库的运行方式以及低水位时内源释放作用有关. 溶解态氮的滞 留效率在 $12 \%-45 \%$ 范围内变化, 年平均值为 $32.0 \%$; 总磷的滞留效率在 $-89 \%$ 至 $80 \%$ 范围内变化, 氮、磷营养盐的滞留 效率满足磷 $>$ 氮. 径流量是引起水库溶解态氮输送通量季节变化的主要影响因子, 浓度是制约磷营养盐滞留的主要 因素.

关键词: 万安水库;营养盐;滞留效应

\section{Retention of nitrogen and phosphorus in Wan' an Reservoir, Jiangxi Province}

\author{
HU Chunhua ${ }^{1,2}$,ZHOU Wenbin ${ }^{1,2}$,ZHONG Xialian ${ }^{1,2}$ \& WANG Maolan ${ }^{1,2}$ \\ ( $1:$ Key Laboratory of Poyang Lake Environmental and Resource Utilization, Ministry of Education, Nanchang University, \\ Nanchang 330029, P. R. China) \\ (2: School of Environmental and Chemical Engineering, Nanchang University, Nanchang 330031, P. R. China)
}

\begin{abstract}
The effects on the total nitrogen(TN) and total phosphorus(TP) retention of the inflows and outflows in Wan'an Reservoir, Jiangxi Province were investigated from 2007 to 2009 . The results indicated that $1.57 \times 10^{4}, 2.38 \times 10^{4}$ and $2.95 \times 10^{4}$ tons of dissolved nitrogen were trapped in Wan'an Reservoir in 2007, 2008 and 2009 respectively, and $7.44 \times 10^{2} \mathrm{t}, 3.65 \times 10^{3} \mathrm{t}$ of TP in 2007 and 2009, respectively. The retention of TP in Wan'an Reservoir appeared negative in 2008, which reflected exogenous input. The retention efficiencies of dissolved nitrogen were the annual average of $32 \%$ with the range of $12 \%-45 \%$, and retention efficiencies of TP were in the range of $-89 \%$ to $80 \%$. It suggested that the retention efficiency of nitrogen was lower than that of phosphorus except for 2008. The river runoff was the main factor of the seasonal changes of TN fluxes, and the nutrient concentration was the restriction factor on the retention of TP.
\end{abstract}

Keywords: Wan'an Reservoir; nutrient; retention efficiency

规模筑坝拦截是当前世界河流普遍面临的共同趋势 ${ }^{[1]}$,人工筑坝形成的水库,在物理、化学及生物等多 个方面区别于天然河流和湖泊,极大地改变了河流的自然环境如水文 ${ }^{[2]}$ 、物质转化、输送通量以及河流生态 环境 ${ }^{[1]}$. 目前, 大坝建设正受到国内外科学家越来越多的重视 ${ }^{[3]}$.

* 国家水体污染控制与治理科技重大专项项目 (2008ZX07526-008-03)、国际科技合作资助项目 (2006DFB91920)、 国家科技支撑计划“十一五”重点项目 (2007BAB23CO2)、江西省经济社会发展重大课题(08ZD801)、国家自然科 学基金项目 (40672159) 和中国经济改革实施技术援助项目 (支援五期 TCC5 : jxspyhzxh09 - 03) 联合资助. 2009 12-02收稿;2010-06-11 收修改稿. 胡春华,男,1976 年生,博士研究生;E-mail : ouyangyinghui@ 126. com. 
赣江是长江的主要支流, 鄱阳湖第一大支流, 也是南昌市主要的饮用水源 ${ }^{[4]}$, 很多重要指标如流域面 积、工农业生产总值均占江西省总量的一半以上 ${ }^{[5]}$. 位于赣江上游的万安水库, 控制流域面积 $36900 \mathrm{~km}^{2}$, 占 赣江全流域面积的 $44 \%$, 其水利枢纽是江西省目前最大的水电工程, 也是赣江干流的控制性工程 ${ }^{[5]}$. 目前, 国内对万安水库的研究集中在水库发电调度、渔业以及移民问题上, 对其营养盐滞留方面的研究相对缺乏, 分析其在河流生态系统中的迁移转化, 并识别其主要影响因素, 对竷江河流生态系统的健康具有重要意义. 此外, 氮、磷营养盐是水体富营养化的主要影响因子 ${ }^{[4,7-9]}$, 赣江在整个长江流域属于清洁水源, 水质较好, 对 其上游万安水库的营养盐滞留的研究, 为鄱阳湖乃至长江水体富营养化的研究具有一定意义. 本文对万安 水库人库、出库氮、磷营养盐浓度分布、输送通量及滞留效率进行分析, 讨论了水库对氮、磷营养盐的滞留效 应,并探讨水库对氮、磷营养盐滞留差异的原因.

\section{1 材料与方法}

\section{1 样品采集及分析}

分别于 $2007-2009$ 年 1 月 (枯水期) 及 8 月 (丰水期) 对万安水库进行 6 次采样, 在人库支流章水(赣州 市西河大桥) 和录水 (赣州市东河大桥) 附近分别设置断面, 每个断面取 3 个采样点, 万安县赣江大桥 (出 库) 设置一个断面, 断面上设置 2 个采样点. 按照国家标准方法测定水样中总磷 ( TP)、硝酸盐 $\left(\mathrm{NO}_{3}-\mathrm{N}\right) 、$ 氨 氮 $\left(\mathrm{NH}_{4}-\mathrm{N}\right)$ 、悬浮颗粒物 $(\mathrm{SS})$ 、浊度. TP 按照 GB-T 11893-1989 标准, 最低检出浓度为 $0.01 \mathrm{mg} / \mathrm{L}$, 测定上限 为 $0.6 \mathrm{mg} / \mathrm{L} ; \mathrm{NO}_{3}-\mathrm{N}$ 按照 $\mathrm{HJ} / \mathrm{T} 346-2007$ 标准, 最低检出浓度为 $0.08 \mathrm{mg} / \mathrm{L}$, 测定下限为 $0.32 \mathrm{mg} / \mathrm{L}$, 测定上限 为 $4 \mathrm{mg} / \mathrm{L} ; \mathrm{NH}_{4}-\mathrm{N}$ 按照 GB-T $7479-1987$ 标准, 最低检出浓度为 $0.05 \mathrm{mg} / \mathrm{L} ; \mathrm{SS}$ 按照 GB $11901-89$ 标准, 浊度 按照 GB $13200-91$ 标准, 最低检测浊度为 3 度.

\section{2 滞留效应的估算方法}

分 3 个层次对万安水库氮、磷营养盐的滞留效应进行估算, 分别是浓度滞留率 $R_{\mathrm{c}}(\%)($ 把氮、磷浓度的 变化率称为浓度滞留率)、输送通量 $F(\mathrm{t})$ 以及实际滞留效率 $R E T_{\mathrm{f}}(\%)^{[10]}$ :

$$
R_{c}=\left(C_{\text {in }}-C_{\text {out }}\right) / C_{\text {in }}, F=C Q, R E T_{\mathrm{f}}=\left(M_{\text {in }}-M_{\text {out }}\right) / M_{\text {in }}
$$

其中, $C_{\text {in }}, C_{\text {out }}$ 分别代表营养盐人、出库浓度 $(\mathrm{mg} / \mathrm{L}) ; Q$ 为径流量; $M_{\text {in }}, M_{\text {out }}$ 分别代表营养盐人、出库 通量.

\section{2 结果与分析}

\section{1 氮、磷营养盐的分布特征}

分别以溶解态氮 ( DIN)、TP 的滞留来表示万安水库对氮、磷营养盐输送的影响. 由于赣江主干流亚硝 酸盐氮 $\left(\mathrm{NO}_{2}-\mathrm{N}\right)$ 含量极少, 且整个赣江流域只有极少数支流检测到 $\mathrm{NO}_{2}-\mathrm{N}^{[4]}$, 故本文中 DIN 的浓度仅以 $\mathrm{NO}_{3}-\mathrm{N} 、 \mathrm{NH}_{4}-\mathrm{N}$ 表示.

万安水库对氮、磷营养盐存在滞留作用, DIN 、TP 的浓度表现为人库 > 出库 (表 1). $2007-2009$ 年, 人库 DIN 的浓度范围是 $1.5-3.0 \mathrm{mg} / \mathrm{L}$, 平均为 $2.29 \mathrm{mg} / \mathrm{L}$, 高于出库 $($ 范围 $1.3-2 \mathrm{mg} / \mathrm{L}$, 平均为 $1.69 \mathrm{mg} / \mathrm{L}$ ) ; TP 人 库的浓度变化范围是 $0.05-1.7 \mathrm{mg} / \mathrm{L}$, 平均为 $0.10 \mathrm{mg} / \mathrm{L}$, 而出库的 $\mathrm{TP}$ 范围是 $0.01-0.06 \mathrm{mg} / \mathrm{L}$, 平均为 $0.034 \mathrm{mg} / \mathrm{L}$. 在丰、枯水期, DIN、TP 的浓度分布特征发生较大变化. 以 2007 年为例, 枯水期人库、出库 DIN 浓度均高于丰水期, 而 TP 却表现为丰水期高于枯水期,2009 年情况正好相反, 表明氮、磷营养盐的分布具有 差异性. 2008 年, DIN 人库平均值是 $2.21 \mathrm{mg} / \mathrm{L}$, 同样高于出库的 DIN (平均值为 $1.51 \mathrm{mg} / \mathrm{L}$ ), 但在枯水期人 库的 TP 浓度较出库低, 表现为磷的内源输人作用.

对 DIN 、TP 的浓度变化率 $\left(R_{\mathrm{c}}\right)$ 分析表明, 水库中磷的浓度滞留率要高于氮. 数据显示, DIN 的年平均 $R_{\mathrm{c}}$ 为 $26.3 \%, \mathrm{TP}$ 为 $58.3 \%$, 是 $\mathrm{DIN}$ 年平均 $R_{\mathrm{c}}$ 的 2.2 倍, 这与国内外一些文献研究结论 ${ }^{[11-12]}$ 相符. 2007 年和 2009 年枯水期 DIN 的平均 $R_{\mathrm{c}}$ 为 $19.8 \%$, TP 为 $71.8 \%$; 丰水期 DIN 的平均 $R_{\mathrm{c}}$ 为 $32.7 \%, \mathrm{TP}$ 为 $51.5 \%$, 不同时 期 DIN 的浓度滞留情况整体表现为:枯水期 <丰水期;TP 的滞留为枯水期 > 丰水期. 
表 1 万安水库不同时期人库、出库的 DIN、TP 浓度

Tab. 1 Concentrations of DIN and TP for inflows and outflows to the Wan' an Reservoir in different periods

\begin{tabular}{cccccc}
\hline \multirow{2}{*}{ 时间 (年一月) } & \multicolumn{2}{c}{$\mathrm{DIN}(\mathrm{mg} / \mathrm{L})$} & & \multicolumn{2}{c}{$\mathrm{TP}(\mathrm{mg} / \mathrm{L})$} \\
\cline { 2 - 3 } \cline { 5 - 6 } & 人库平均值 & 出库平均值 & & 人库平均值 & 出库平均值 \\
\hline $2007-01$ & 2.23 & 1.96 & & 0.05 & 0.03 \\
$2007-08$ & 2.32 & 1.50 & & 0.08 & 0.05 \\
$2008-01$ & 1.52 & 1.36 & & 1.67 & 3.16 \\
$2008-08$ & 2.92 & 1.67 & & 0.08 & 0.04 \\
$2009-01$ & 2.69 & 1.96 & & 0.13 & 0.01 \\
$2009-08$ & 1.92 & 1.35 & & 0.14 & 0.06 \\
\hline
\end{tabular}

\section{2 氮、磷营养盐的输送规律}

径流量的数据来自吉安市水文局、江西省统计年 鉴 ${ }^{[13]}$ 以及相关文献 ${ }^{[14]}, 2007-2009$ 年,万安水库 $1 、 8$ 月份流量的多年平均值变化范围为 $160-940 \mathrm{~m}^{3} / \mathrm{s}$, 见 图 1. 受季节性降水的影响, 丰水期平均流量为枯 水期平均流量的 3 倍, 流量年内丰水期高、枯水期低 的分布特征明显.

万安水库氮、磷营养盐的月输送通量可以看出 (图 2), 氮营养盐表现为: DIN 的月输送通量与径流 量(图 1) 之间有较为一致的变化规律. 人库、出库 的 DIN 月输送通量与径流量之间呈显著正相关 (人 库 $r=0.79$, 出库 $r=0.94, P<0.05)$, 表明径流量是 引起水库 DIN 输送通量季节变化的主要影响因子. 从人库、出库的月通量来看, DIN 人库通量要高于出 库通量. 2007-2009 年水库的人库平均月输送通量

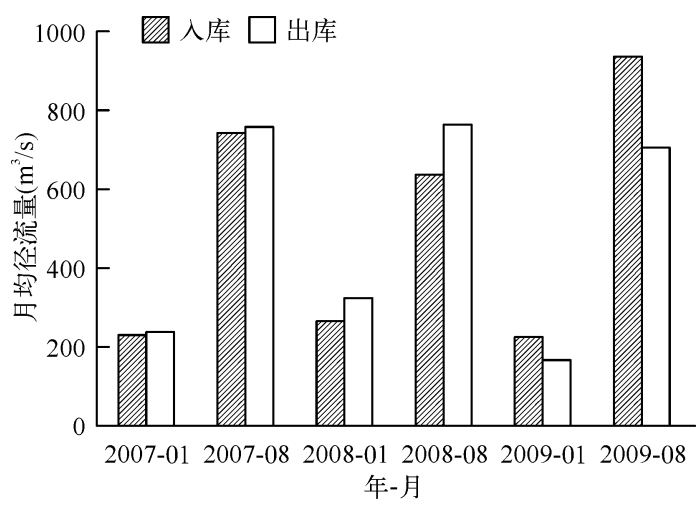

图 1 2007-2009 年万安水库人库、出库月均径流量

Fig. 1 Monthly runoff of DIN and TP for inflows and outflows to the Wan' an Reservoir in different periods during $2007-2008$ 分别为 $3.01 \times 10^{4} \mathrm{t} 、 3.39 \times 10^{4} \mathrm{t} 、 2.76 \times 10^{4} \mathrm{t}$, 出库通量分别为 $2.05 \times 10^{4} \mathrm{t} 、 2.02 \times 10^{4} \mathrm{t} 、 1.90 \times 10^{4} \mathrm{t}$, 三年之间分 别有 $9.68 \times 10^{2} \mathrm{t} 、 1.37 \times 10^{3} \mathrm{t} 、 8.54 \times 10^{2} \mathrm{t}$ 氮滞留于水库内. 从季节变化来看, 丰水期水库的月输送通量明显 高于枯水期, 并且营养盐在丰水期的滞留量也远高于枯水期. 数据显示, 丰水期的平均 DIN 月输送通量为 $3.83 \times 10^{3} \mathrm{t}$, 远高于枯水期 $\left(1.22 \times 10^{3} \mathrm{t}\right)$; 丰水期的 DIN 月滞留量约为枯水期的 8 倍. 对磷营养盐而言: TP 的月输送通量与径流量之间存在一定负相关, 但并不明显( 人库 $r=-0.17$, 出库 $r=-0.25, P<0.05$ ), 表明 径流量对 TP 输送通量的季节变化影响不大. 从人库、出库的月通量来看, 万安水库对 TP 存在一定滞留作
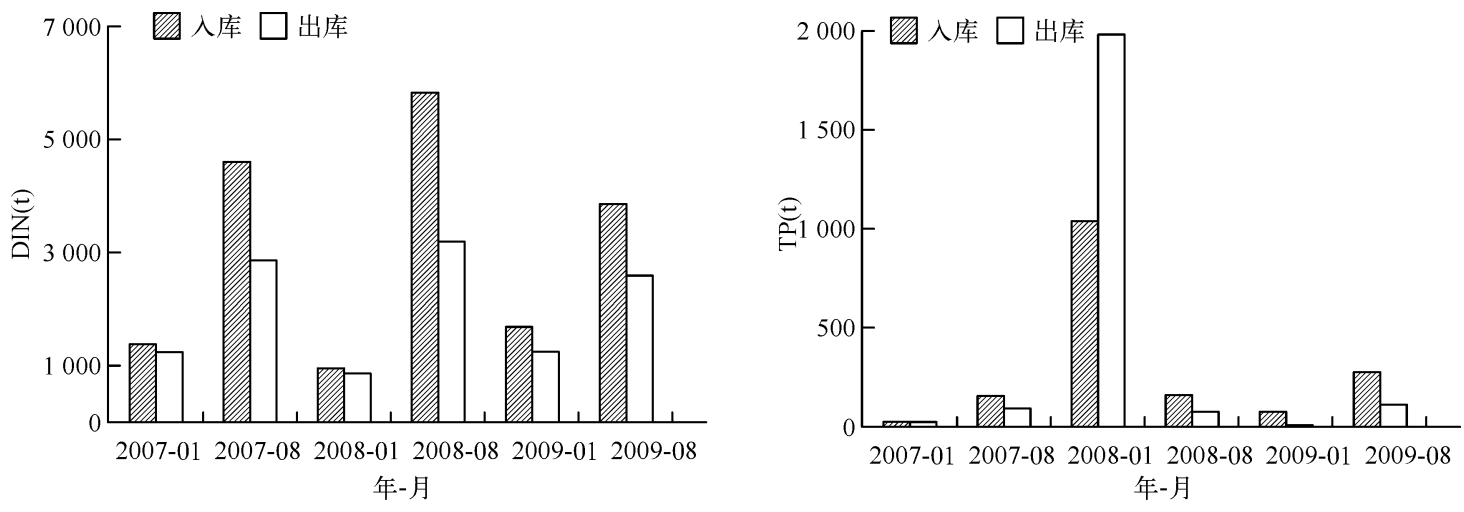

图 2 万安水库不同时期人库、出库氮、磷营养盐的月通量

Fig. 2 Monthly fluxes of DIN and TP for inflows and outflows to the Wan' an Reservoir in different periods 
用. 2007 年和 2009 年水库 TP 的月平均滞留量分别 $38.4 \mathrm{t} 、 1.25 \times 10^{2}$ t. 除 2008 年枯水期之外, 水库对 TP 均 表现为滞留作用. 2008 年枯水期 TP 呈现负滞留, 且滞留量异常 $\left(-9.33 \times 10^{2} \mathrm{t}\right)$, 表明不同时期 TP 的滞留通 量变化较大,规律不明显.

根据万安水库人库、出库的年平均径流量对氮、磷营养盐的年输送通量进行估算, 结果可以看出, 氮营 养盐表现为: 2007-2009 年间水库 DIN 的年滞留量分别为 $1.57 \times 10^{4} \mathrm{t} 、 2.38 \times 10^{4} \mathrm{t} 、 2.95 \times 10^{4} \mathrm{t}$ (表 2 ), 呈逐 年增加的趋势, 这主要受年均径流量的影响. 数据显示, 水库人库、出库 DIN 年输送通量与径流量密切相关 ( 人库 $r=0.97$, 出库 $r=0.92, P<0.01$ ), 说明 DIN 年输送通量的计算中流量是主要影响因子, 又由于人库 年径流量从 2007-2009 年逐年增加, 而出库流量却逐年减少, 因而水库对 DIN 的滞留通量会增加. 对磷营 养盐而言:三年间, 分别有 $7.44 \times 10^{2} \mathrm{t} 、-2.13 \times 10^{4} \mathrm{t} 、 3.65 \times 10^{3} \mathrm{t}$ 的 TP 滞留于库内, 年通量变化较大, 这主 要是由于 TP 的年平均浓度差异较大. TP 年平均浓度以 2008 年为最大, 且其值比 2007 和 2009 年高出 2 个 数量级, 因而通量的计算中浓度成为了主要影响因子. 相关性分析发现, TP 的年输送通量与对应的浓度呈 显著正相关 $(r>0.99, P<0.05)$.

表 2 2007-2009 万安水库氮、磷营养盐的年输送通量

Tab. 2 Yearly fluxes of DIN and TP to the Wan'an Reservoir in different periods during 2007 - 2009

\begin{tabular}{|c|c|c|c|c|c|c|c|c|}
\hline \multirow{2}{*}{ 时间 } & \multicolumn{2}{|c|}{ 年均径流量 $\left(\times 10^{8} \mathrm{~m}^{3}\right)$} & \multicolumn{3}{|c|}{$\operatorname{DIN}(t)$} & \multicolumn{3}{|c|}{$\mathrm{TP}(\mathrm{t})$} \\
\hline & 人库 & 出库 & 人库总量 & 出库总量 & 滞留量 & 人库总量 & 出库总量 & 滞留量 \\
\hline 2007 年 & 307 & 312 & $6.98 \times 10^{4}$ & $5.40 \times 10^{4}$ & $1.57 \times 10^{4}$ & $1.99 \times 10^{3}$ & $1.25 \times 10^{3}$ & $7.44 \times 10^{2}$ \\
\hline 2008 年 & 316 & 305 & $7.01 \times 10^{4}$ & $4.63 \times 10^{4}$ & $2.38 \times 10^{4}$ & $2.76 \times 10^{4}$ & $4.89 \times 10^{4}$ & $-2.13 \times 10^{4}$ \\
\hline 2009 年 & 337 & 299 & $7.47 \times 10^{4}$ & $4.52 \times 10^{4}$ & $2.95 \times 10^{4}$ & $4.54 \times 10^{3}$ & $8.96 \times 10^{2}$ & $3.65 \times 10^{3}$ \\
\hline
\end{tabular}

\section{3 氮、磷营养盐的滞留效率}

万安水库氮、磷的滞留效率可知, $2007-2009$ 年间水库对氮均表现出正滞留,对磷则可能是负滞留. DIN 的滞留效率在 $10 \%-45 \%$ 范围内变化, 月平均值为 $27.5 \%$,年平均值为 $32.0 \%$; TP 的滞留效率在 $-89 \%$ 至 $80 \%$ 范围内变化, 2008 年枯水期出现负值, 同时也造成 2008 年的年均效率为负值 (图 3). 从时间变化来 看, DIN 的滞留整体呈现较稳定的周期性变化,2007 年枯水期处于较低水平,到 2007 年丰水期有较大提高, 至下一个枯水期又降低,依次变化, 最大值出现在 2008 年丰水期, 为 $45.3 \%$,最小值出现在 2008 年枯水期, 为 10.3\%; TP 的滞留作用呈波动幅度较大的周期性变化, 最大值出现在 2009 年枯水期, 为 $97.7 \%$; 最小值出 现在 2008 年的枯水期, 为 $-89.7 \%$. 除 2008 年枯水期以外,水库对磷的滞留作用高于氮, $2007 、 2009$ 年枯水 期表现尤为明显, 分别有 $11.9 \% 、 26.9 \%$ 的氮滞留于水库内, 而同期分别有 $39.8 \% 、 97.7 \%$ 的磷滞留于水库 内, 磷的滞留效率约为氮的 2.5 倍; $2007-2009$ 年丰水期滞留差异则不明显.
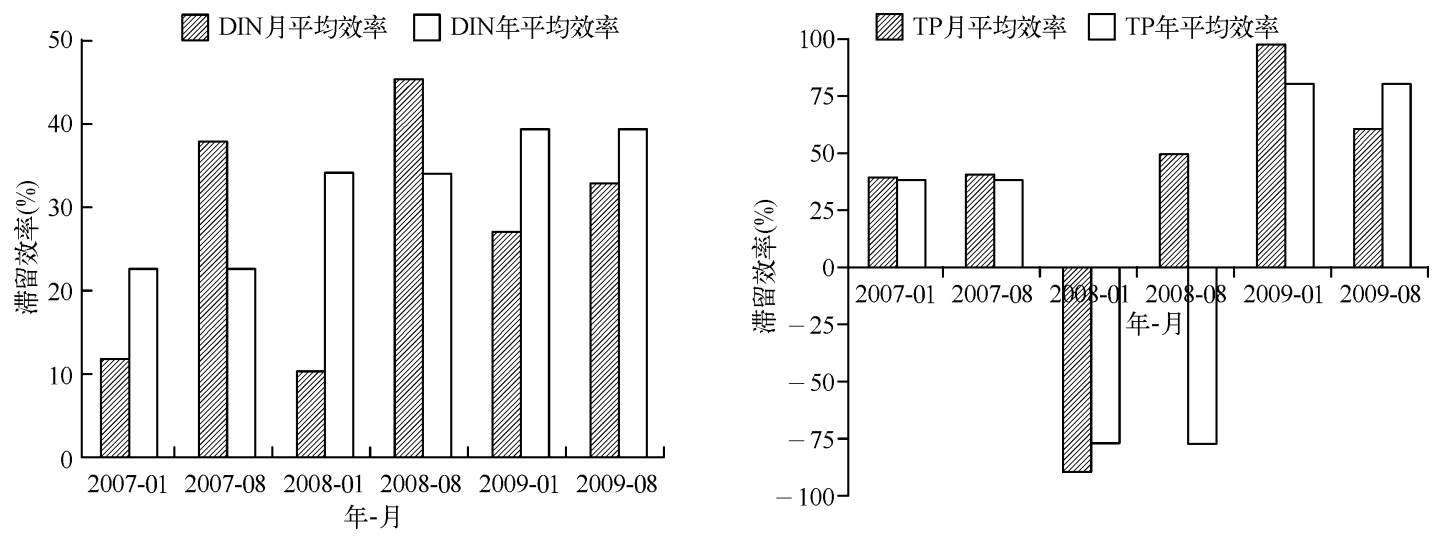

图 3 万安水库不同时期 DIN 、TP 的滞留效率 $\left(R E T_{\mathrm{f}}\right)$

Fig. 3 DIN and TP retention efficiency of Wan'an Reservoir in different periods $\left(R E T_{\mathrm{f}}\right)$ 


\section{4 万安水库对氮、磷营养盐的滞留效应及原因分析}

万安水库每年滞留超过 $22 \%$ 的溶解态氮, 2007-2009 年平均 DIN 滞留总量为 $2.30 \times 10^{4} \mathrm{t}$, 滞留效率为 $31.9 \%$ (表 2). 水库对磷也有显著的滞留作用,并且磷的滞留作用比氮的滞留作用更显著. 2007、2009 年万 安水库磷输送量分别为 $1.99 \times 10^{3} \mathrm{t} 、 4.54 \times 10^{3} \mathrm{t}$, 水库滞留量分别为 $7.44 \times 10^{2} \mathrm{t} 、 3.65 \times 10^{3} \mathrm{t}$, 相应的滞留效率 为 $37.3 \% 、 80.3 \%$; 同期水库中氮的滞留效率分别为 $22.6 \% 、 39.4 \%$. 可见,水库对磷的滞留作用大于氮. 生 物作用产生一定影响, 这种作用主要表现为浮游植物对营养盐的利用 ${ }^{[15]}$, 水库效应还引起河流水流变缓、透 明度增加, 导致浮游藻类生物量增加, 从而使溶解态营养盐从河流中去除; 而随后的生物遗骸的沉积, 使得 营养盐从河水中被去除. 此外, 河流筑坝形成水库将引起河流水动力学条件的改变, 导致颗粒物沉积作用加 速, 从而使颗粒物携带的营养盐从河流中去除, 并通过絮凝、吸附作用去除水体中溶解态和胶态物质 (如, 颗 粒物对磷酸盐的存在一定的吸附作用 ${ }^{[11,16-17]}$ ). 结合测得的 SS 的数据可知, 出库后, 河流中的 SS 的浓度明 显低于人库以及水库中的浓度 (出库口为 $3.35 \mathrm{mg} / \mathrm{L}$, 人库口的平均 $S S$ 浓度为 $15.2 \mathrm{mg} / \mathrm{L}$, 水库平均为 $10.2 \mathrm{mg} / \mathrm{L}$ ). 可见, 水库内颗粒物沉积在一定程度上减少了河流物质输出. 此外, 诸如脱氮反应也使得输人 到水库中氮的总量减少, 从数值上表现为水库的滞留作用. 对水库人库、出库氮磷比值分析可知, 万安水库 浮游生物的生长受到磷营养盐的限制. 水库人库 $\mathrm{N} / \mathrm{P}$ 比值在 $0.92-44.6$ 之间, 平均值为 24.2 ; 出库的 N/P 范围为 $0.43-653$, 平均值为 135 , 远高于 Redfield 比值, 且出库高于人库. 这主要由于研究的范围磷营养盐 的浓度较低,水库水体对磷营养盐又有更为显著的滞留作用,使得水库输出水体具有高 N/P 比.

2008 年枯水期的 TP 为负滞留, 同期 TP 的人库总量为 $1.04 \times 10^{3} \mathrm{t}$, 出库总量为 $1.97 \times 10^{3} \mathrm{t}$, 滞留量 $-9.33 \times 10^{2} \mathrm{t}$, 滞留效率为 $-89.7 \%$, 即 2008 年枯水期水库对 TP 没有滞留, 而是存在一定的添加作用. 原因 可能是与外源输人、低水位时内源释放作用及水库运行方式有关. 在枯水期, 水库一般低水位运行, 底部较 高浓度的营养盐排放可能在表观上造成负滞留. 有研究 ${ }^{[15]}$ 也指出, 水库营养物浓度在垂向存在分层, 深层 的营养物浓度较表层要高.

\section{3 参考文献}

[ 1 ] 刘丛强,汪福顺,王雨春等. 河流筑坝拦截的水环境响应——来自地球化学的视角. 长江流域资源与环境, 2009,18 (4) : 384-396.

[2] 陈庆伟, 刘兰芬, 刘昌明. 筑坝对河流生态系统的影响及水库生态调度研究. 北京师范大学学报 (自然科学版), $2007, \mathbf{4 3}(5)$ : $578-582$.

[ 3 ] 苒祥滨,于志刚,姚庆祯等. 水库对河流营养盐滞留效应研究进展. 湖泊科学,2009,21(5):614-622.

[4] 王毛兰,周文斌,胡春华. 枯水期贑江流域氮磷的分布特征. 地球与环境, 2007,35(2):166-170.

[ 5 ] 邓义祥, 陈吉宁, 程声通. 稀疏数据下复杂流域的水质模拟: 以赣江为例. 环境科学学报, 2003,23(4) :422-427.

[ 6 ] 黄养仁,黄扬一.万安水库工程地质分析. 人民长江,1996,27(11):41-43.

[ 7 ] 王 孟,邬红娟, 马经安. 长江流域大型水库富营养化特征及成因分析. 长江流域资源与环境, 2004,13 (5): 477-481.

[ 8 ] 李 宝,范成新,丁土明等. 滇池福保湾沉积物磷的形态及其与间隙水磷的关系. 湖泊科学, 2008, 20 (1) :27-32.

[ 9 ] 钟继承,刘国锋,范成新等. 湖泊底泥疏浚环境效应: I. 内源磷释放控制作用. 湖泊科学, 2009,21(1):84-93.

[10］再祥滨.三峡水库营养盐分布特征与滞留效应研究 [ 学位论文].青岛:中国海洋大学,2009.

[11] Garnier J, Leporcq B, Sanchez N et al. Biogeochemical mass-balance ( C, N, P, Si) in three large reservoirs of the Seine Basin(France). Biogeochemistry, 1999,47:119-146.

[12] Uhlman D, Hupfer M, Paul L. Longitudinal gradients in the chemical and microbial composition of the bottom sedimentation in a channel reservoir(Saidenbach, Saxony). Int Revueges Hydrobiol,1995,80 : 15-25.

[13］江西省统计局,国家统计局江西调查总队. 江西统计年鉴. 北京: 中国统计出版社, 2008-2009.

[14] 李天碧. 浅谈万安水利枢纽下游河段设计水位的确定. 水运工程,2003,(9):45-47.

[15] Kimmel BL, Lind OT, Paulson LJ. Reservoir primary production. In:Thornton KW, Kimmel BL, Payne FE eds. Reservoir limnology : Ecological perspectives. New York: John Wiley \& Sons Inc, 1990:133-194.

[16] 张 路,范成新, 朱广伟等. 长江中下游湖泊沉积物生物可利用磷分布特征. 湖泊科学, 2006, 18 (1):36-42.

[17] Kelly VJ. Influence of reservoirs on solute transport: a regional-scale approach. Hydrological Processes, 2001, 15:1227-1249. 